\title{
ANÁLISE DE PARAMETROS FÍSICOS QUÍMICOS DO CÓRREGO DO VEADO, LIMOEIRO E BALNEÁRIO DA AMIZADE EM PRESIDENTE PRUDENTE - SP
}

\section{ANALYSIS OF PARAMETERS CHEMICAL PHYSICIANS OF THE STREAM DEER, LEMON TREE AND BALNEARY OF FRIENDSHIP IN PRUDENT PRESIDENTE - SP}

\author{
John Lennon Benedito da Silva ${ }^{1}$; João Victor Carvalho de Andrade ${ }^{2}$; Maria \\ Yasmim Franco Pereira ${ }^{3}$. \\ ${ }^{1}$ Universidade do Oeste Paulista - UNOESTE, Faculdade de Engenharia, Curso de \\ Engenharia Ambiental e Sanitária, Presidente Prudente, SP. \\ E-mail: John john silva@hotmail.com
}

RESUMO - A vida na terra baseia-se em alguns elementos, entre eles, um dos mais importantes e responsáveis pela vida, a água, uma vez que, onde há água, há vida. Sendo assim, este estudo tem por objetivo mostrar análises laboratoriais de alguns córregos afim de saber se o local está sofrendo alguma influência, seja ela antrópica ou natural no período do ano de 2016, dispondo de análises laboratoriais para auferir dados que comprovem a situação do rio, até mesmo a deficiência ou abundancia de algum parâmetro analisado como oxigênio, pH, turbidez, condutividade e temperatura. Com essas análises obtivemos valores que mostram o comportamento do leito em tempos de estiagem e de chuvas onde por vez tem mostrados valores bem esperados e satisfatórios por ser um leito onde em tempos passados recebiam grandes quantidades de efluentes.

Palavras-chave: Água, Autodepuração, Córrego, Poluentes, Rio.

ABSTRACT - Life on earth is based on some elements, among them one of the most important and responsible for life, water, since, where there is water, there is life. Therefore, this study aims to show laboratory analyzes of some streams in order to know if the site is undergoing any influence, be it anthropic or natural in the period of 2016 , having laboratory analyzes to obtain data that prove the situation of the river, even the deficiency or abundance of some parameter analyzed as oxygen, $\mathrm{pH}$, turbidity, conductivity and temperature. With these analyzes we obtained values that show the behavior of the bed in times of drought and rainfall where at the same time it has shown well expected and satisfactory values because it is a bed where in the past they received large amounts of effluents.

Keywords: Water, Autodepuration, Stream, Pollutants, River. 


\section{INTRODUÇÃO}

Com grande crescimento populacional na região do Oeste Paulista, Presidente Prudente se encontra entre as cidades mais populosas com cerca de 208 mil habitantes (IBGE- Instituto Brasileiro de Geografia e Estatística) e frequentadas devidos as suas grandes variedades de atrações, comércios, empregos, universidades e outros. As cidades industriais destacam-se como as que apresentam maior consumo per capita, em consequência dos gastos elevados de água, que geralmente se verificam na maior parte das indústrias (Guimarães; Carvalho e Silva, 2007, p.39). Devido a esses fatores a utilização do recurso hídrico encontra em altas utilidades, seja ela para fins comerciais, urbanos e lazer vários problemas podem e devem ocorrer pela falta de destinação correta dos efluentes ou por uma má drenagem urbana, onde grandes concentrações de poluentes seja eles líquidos ou sólidos se encontram em corpos hídricos, com esse objetivo uma análise foi desenvolvida para determinar o que ocorre no momento e local de onde foi coletado as amostras, essas análises tem por fim determinar se o leito passa por uma autodepuração ou está sofrendo alguma reação seja ela natural ou antrópica. O processo de autodepuração se completa com a reposição, pela reaeração, deste oxigênio consumido (Machado, Márcio Bezerra, 2006, p.19). Ao decorrer de todo o ano uma coleta foi feita cujo período do ano o leito sofre um défice ou um superávit de algum parâmetro seja ele físico ou químico.

O objetivo geral desse trabalho foi analisar e diagnosticar os parâmetros físicos e químicos de um local de três córregos de Presidente Prudente sendo eles o Córrego do Veado, Limoeiro e Balneário.

Com o objetivo de atingir o geral foi feito os seguintes procedimentos de análises para possíveis comparações em cada mês afim de coletar informações de Oxigênio, Condutividade, pH (potencial Hidrogeniônico), Turbidez e Temperatura.

\section{METODOLOGIA}

Foi determinado um local fixo para a coleta das amostras e análises no local para que seja padronizado e obtidos resultados com um padrão oferecido pelo local.

Utilização de equipamentos de laboratórios tais como frascos de amostra de líquidos, aparelhos eletrônicos que meçam os parâmetros exigidos citados no objetivo, EPI (Equipamentos de Proteção Individual), coordenadas geográficas através de softwares do Google e Google Earth.

\section{ANÁLISE DE ÁGUA}

Obedecendo a diretriz nacional nos padrões realizados pelo ministério da Saúde no departamento de vigilância em saúde ambiental e saúde do trabalhador foram determinadas suas importâncias em análise.

As coletas foram realizadas no período de duas horas (09-11horas), (12 - 13horas) e (14 18horas), obedecendo os locais e a profundidade mínima exigida de $20 \mathrm{~cm}$, com frascos de volume de $200 \mathrm{ml}$.

Como primeiro ponto de coleta o Córrego do Limoeiro situado dentro do Campus II da UNOESTE e sofre influência antrópica principalmente a partir de um de seus afluentes o Córrego do Veado foi definido como ponto de coleta jusante aos pedregulhos e montante da ponte cujo localizado pelas coordenadas geográficas na latitude (2207'02" S) e longitude (5127'15” W).

O segundo ponto de coleta cujo foi no Córrego do Veado foi a jusante do estrangulamento do leito e montante de sua parte mais fina do leito cujo a localizado pelas coordenadas geográficas na latitude (2206 '47" S) e longitude (5126'39" W).

O terceiro ponto de foi no Córrego do Balneário da Amizade a jusante da APP (Área de Preservação Permanente) do balneário onde determinado a montante do ponto mais raso do leito e situado no local mais estreito do mesmo cujo localizado pelas coordenadas geográficas na latitude (2206 ${ }^{\prime} 37^{\prime \prime}$ S) e longitude (51⒉ $\left.26^{\prime} 46^{\prime \prime} \mathrm{W}\right)$.

Parâmetros analisados e metodologia utilizada para a realização dos experimentos. 
Tabela 1. Parâmetros analisados e metodologia utilizada para a realização dos experimentos.

\begin{tabular}{|c|c|c|}
\hline Parâmetro & Método & Referência \\
\hline $\mathrm{pH}$ & Potenciométrico & $\begin{array}{c}\text { SMWW, 21a Edição, Método } \\
45000-\mathrm{H}+2\end{array}$ \\
\hline Turbidez & Nefelométrico & $\begin{array}{c}\text { MWW, 21a Edição, Método } 2130 \\
\text { - B }\end{array}$ \\
\hline Oxigênio & Eletrodo de membrana & $\begin{array}{c}\text { SMWW, 22a Edição, } 2012 \text { Método } \\
45000 \mathrm{G}\end{array}$ \\
\hline Condutividade & Condutivimetro & $\begin{array}{l}\text { SMWW, 22a Edição, Método } \\
\text { 2510B }\end{array}$ \\
\hline Temperatura & Termômetro & $\begin{array}{c}\text { SMWW, 22a Edição, Método } \\
\text { 2550B }\end{array}$ \\
\hline
\end{tabular}

Fonte: Inmetro, adaptado, 2018.

\section{RESULTADOS E DISCUSSÕES}

Todas as análises de água foram feitas em laboratórios cujo os dados foram anotados e levantados em planilha do Excel e exibidos na forma de tabela para uma melhor visualização nas tabelas e gráficos abaixo.

Gráfico 1. Gráfico simplificado dos dados da tabela 1do Limoeiro situado dentro do Campus II.

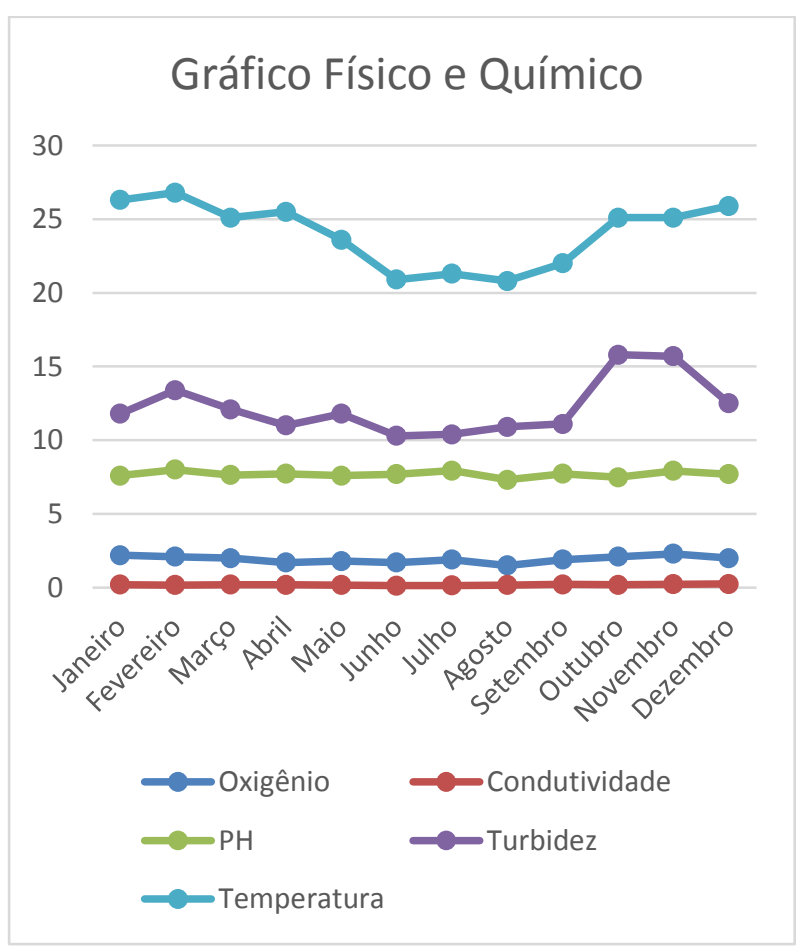

Fonte: Acervo pessoal do autor, 2016.

O gráfico mostra que nos meses de outubro a fevereiro onde há pequenas chuvas porem intensas, sua turbidez apresentou um valor a mais do que os outros meses de abril a setembro. 
Gráfico 2. Gráfico simplificado dos dados da tabela 2, referente ao Córrego do Veado.

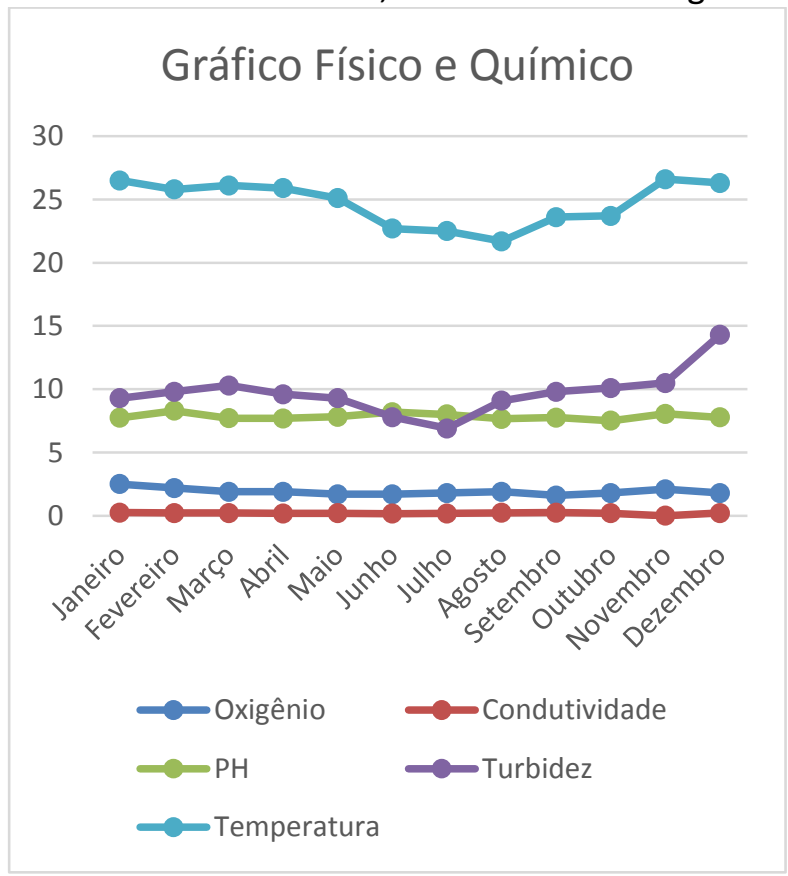

Fonte: Acervo pessoal do autor, 2016.

Devido a um presente efluente no local cujo gerou espuma houve uma alteração na turbidez do efluente no mês de julho, e nos outros demais meses houve um aumento gradativo ao decorrer do tempo, enquanto os outros parâmetros apresentam normalidade em relação ao córrego do Limoeiro.

Gráfico 3. Resultados obtidos pelas análises laboratoriais referente ao Córrego do Balneário da Amizade.

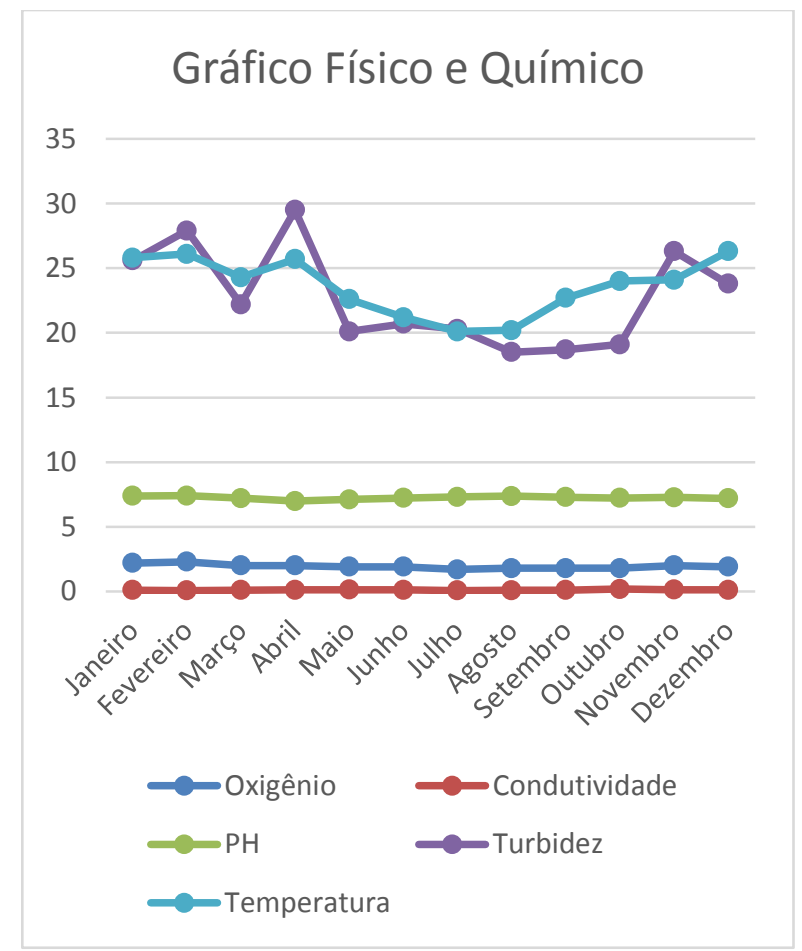

Fonte: Acervo pessoal do autor, 2016.

No Gráfico 3, podemos perceber uma grande oscilação em relação a temperatura e turbidez do leito devido as chuvas nos meses em que se encontra no verão, pois quando o mesmo ocorria a represa do Balneário se encontrava com uma vazão muito mais alta fazendo com que o 
fluxo do leito aumentasse e consequentemente a turbidez também.

De acordo com a classificação de Köppen, o clima da região de Presidente Prudente é do tipo "Awa" - tropical com estação chuvosa no verão e seca no inverno, onde a temperatura no mês mais quente é superior a $22 \stackrel{\circ}{ } \mathrm{C}$, e a do mês mais frio é superior a 18 oC. O clima regional, classificado como "Aw", tropical quente úmido, é perturbado pela circulação atmosférica regional, que confere a condição de transição climática, caracterizado por variabilidade pluviométrica, com flutuações no total de chuvas devidas a características geográficas locais (Koppen,2012).

\section{CONCLUSÃO}

Devidos a vários fatores presente no cotidiano e pelas amostras serem sempre coletadas em dias não chuvosos ou com anormalidades naturais obtivemos valores e resultados bem próximos dos padrões, pois os grandes feitos ou acontecimentos já poderiam ou iriam ocorrer durante e após as coletas, com tudo, obtivemos valores bem tolerantes e dentro dos esperados por serem locais de dificuldade de acesso antrópico e por ser um ambiente sem a presença de stress natural.

\section{REFERÊNCIAS}

POPULAÇÃO no último censo: Presidente Prudente. 2018. Disponível em: <https://cidades.ibge.gov.br/brasil/sp/presidente -prudente/panorama>. Acesso em: 08 ago. 2018.

CARVALHO E SILVA, Guimarães. Saneamento Básico II. UNIVASF: [s.n.], [Agosto 2017]. 39 p. Disponível em: <http://www.ufrrj.br/institutos/it/deng/leonardo /downloads/APOSTILA/Apostila\%20IT\%20179/Ca p\%204\%20parte\%201.pdf>. Acesso em: 08 maio 2018.

MARCIO BEZERRA, Machado. Modelagem Tridimensional da Dispersão de Poluentes em Rio: Desenvolvimento de Processos Químicos. 2007.

GEIGER, Köppen et al. Classificação climática de Köppen-Geiger. 2000. Disponível em: $<$ https://portais.ufg.br/up/68/o/Classifica___o_ Clim_tica_Koppen.pdf $>$. Acesso em: 08 ago. 2018.
SOARES, Fernanda. SUBSÍDIOS PARA O PLANEJAMENTO AMBIENTAL: ESTUDO DE CASO DA BACIA DO BALNEÁRIO DA AMIZADE - SÃO PAULO. Presidente Prudente-SP: [s.n.], 2015. 278 p. $\quad$ v. 22. Disponível em: <http://revista.fct.unesp.br/index.php/formacao/ article/viewFile/3300/3079>. Acesso em: 08 ago. 2018.

ESCOPO DA ACREDITAÇÃO - ABNT NBR ISO/IEC 17025 - ENSAIO. 22. ed. [S.I.: s.n.], 2012. 4 p. Disponível em: <http://www.inmetro.gov.br/laboratorios/rble/d ocs/CRL0105.pdf>. Acesso em: 08 ago. 2018. 